\title{
Optimising the Yield of Silicon Carbide Synthesised from Indigenous Biomass Husk using Different Catalysts
}

Khalil Ahmad', Muhammad Ali ${ }^{\star 2}$, Ather Ibrahim ${ }^{2}$ and Waqas Mehmood Baig ${ }^{2}$

${ }^{1}$ Department of Metallurgical \& Materials Engineering, University of Engineering \& Technology, Lahore-54890, Pakistan

${ }^{2}$ Institute of Advanced Materials, Bahauddin Zakariya University, Multan-60800, Pakistan

\begin{abstract}
Biomass husk is a cost effective source to produce silicon based ceramics. Present work deals with the catalytic synthesis of silicon carbide from biomass husk of indigenous rice as raw materials. Rice husk samples were treated with different concentrations of sodium silicate, $40 \%$ hydrochloric acid and a mixture of $40 \% \mathrm{HCl}$ and $2 \mathrm{gl}^{-1} \mathrm{Na}_{2} \mathrm{SiO}_{3}$. Treated husk were pyrolysed at $1350^{\circ} \mathrm{C}$ in argon atmosphere and then oxidised to eliminate unreacted carbon. Products were characterised by XRD, SEM and EDS techniques in order to confirm the carbide formation, to identify carbide morphology and to conduct elemental analysis respectively.Maximum yield was obtained in case of catalytic treatment with $2 \mathrm{gll}^{-1} \mathrm{Na}_{2} \mathrm{SiO}_{3}$. Acid treatment, although showed no considerable increase in yield, fostered whiskers formation instead of particles.
\end{abstract}

Keywords: Silicon carbide; Whiskers; Sodium silicate; Pre-treatment; Pyrolysis; Catalysis

\section{Introduction}

Silicon carbide offers a wide spectrum of electrical, chemical and mechanical properties, for which it is used in a variety of modern applications [1]. Silicon Carbide has high density, good thermal conductivity, extreme hardness, excellent corrosion and thermal shock resistance. These versatile properties enable it to beused in high temperature and structural applications. Due to high energy band gap and saturated drift velocity, it is also used for high temperature semiconductor material as compared to silicon based materials [2]. High purity silicon carbide can be synthesised from rice husk (RH) which generally contains $71-87 \mathrm{wt} \%$ organic components such as cellulose, lignin and sugar [3], and 13-29 wt\% inorganic components. Oxidation of RH vaporizes the organic part and residual inorganic component is termed as rice husk ash (RHA) [4,5] more than $95 \%$ of which comprises ultrafine silica [6]. RHA is being used for some specific purposes such asceramic glaze, insulator, roofing shingles, waterproofing chemicals, oil spill absorbent specialty paints, flame retardants, carrier for pesticides and insecticides, fertilizer conditioner and zeolites synthesis [7]. The formation of $\mathrm{SiC}$ from $\mathrm{RH}$ pyrolysis is accomplished in a single or two stages. In single stage method, $\mathrm{RH}$ is pyrolysed at $1300-1500^{\circ} \mathrm{C}$ [8]. The amorphous silica in the RH can produce silicon carbide, silicon nitride, silicon oxynitride, pure silicon and other silicon based compounds depending upon the composition, atmosphere, reaction temperature and pre-pyrolysis treatment. However, the following chemical reactions occur during the carbothermal reduction of $\mathrm{RH}$ in the inert or reducing atmosphere at elevated temperatures [9]:

$$
\begin{aligned}
& \mathrm{SiO}_{2}(\mathrm{~s})+3 \mathrm{C}(\mathrm{s}) \rightarrow \mathrm{SiC}(\mathrm{s})+2 \mathrm{CO}(\mathrm{g}) \\
& \mathrm{SiO}_{2}(\mathrm{~s})+2 \mathrm{C}(\mathrm{s}) \rightarrow \mathrm{Si}(\mathrm{s})+2 \mathrm{CO}(\mathrm{g}) \\
& \mathrm{SiO}_{2}(\mathrm{~s})+\mathrm{C}(\mathrm{s}) \rightarrow \mathrm{SiO}(\mathrm{g})+\mathrm{CO}(\mathrm{g})
\end{aligned}
$$

And overall reaction is:

$$
\mathrm{SiO}_{2 \text { (amorphous) }}+3 \mathrm{C}_{\text {(amorphous) }} \rightarrow \mathrm{SiC}_{\text {(crystalline) }}+2 \mathrm{CO} \text { (gas) }
$$

Prior to pyrolysis, $\mathrm{RH}$ can be subjected to various catalytic treatments. Pyrolysis of $\mathrm{HCl}$ treated $\mathrm{RH}$ led to improved yield of $\mathrm{SiC}$ as compared that obtained from untreated raw $\mathrm{RH}$ [10]. RH can be treated with alkaline solution such as that of sodium hydroxide.Sodium silicatecan also be used as catalyst and has been proved beneficial in order to get enhanced yield of the products [11]. Using hydrated cobalt chloride and hydrated iron chloridealong with ammonium hydroxideas catalysts produce silicon carbide at comparatively low temperatures [12]. A study on pyrolysis of RHin the plasma arc reactor under argon atmosphere inferred that considerable product yield can be obtained in very short time [13]. Some other useful catalytic treatments include the use of iron chloride, cobalt chloride and nickel chloride [9].

\section{Experimental Work}

$\mathrm{RH}$ was pre-treated with three different reagents, viz. $\mathrm{Na}_{2} \mathrm{SiO}_{3}, \mathrm{HCl}$ and $\mathrm{HCl}+\mathrm{Na}_{2} \mathrm{SiO}_{3}$. Firstly, samples were prepared by soaking $\mathrm{RH}$ for $24 \mathrm{~h}$ in solutions of different concentrations of $\mathrm{Na}_{2} \mathrm{SiO}_{3}$ in distilled water ranging from 1-6 g/l(designated as A1-A6). Secondly, $\mathrm{RH}$ was boiled in $5 \mathrm{~N} \mathrm{HCl}$ solution for $1 \mathrm{~h}$. Acid treated rice husk (B1) was thoroughly rinsed with distilled water. For the third category $(\mathrm{C} 1)$, $\mathrm{RH}$ was boiled in $5 \mathrm{~N} \mathrm{HCl}$ solution for $1 \mathrm{~h}$, thoroughly washed with distilled water, dried at $90^{\circ} \mathrm{C}$ for sufficient time and then soaked in 2 $\mathrm{g} / \mathrm{l}$ solution of $\mathrm{Na}_{2} \mathrm{SiO}_{3}$ in distilled. All the samples were ground tomesh and stored in a drying oven. Finely ground and dried RHwere subjected to different processes including direct pyrolysis, oxidation of pyrolysed powder to remove residual carbon and finally $\mathrm{HF}$ treatment to remove $\mathrm{SiO}_{2}$ and get pure $\mathrm{SiC}$ powder.

Pre-treated samples were pyrolysed one by one in SentroTech (STT-1650) tube furnace that was heated from ambient to $1350^{\circ} \mathrm{C}$ at a constant rate of $5^{\circ} \mathrm{Cmin}^{-1}$, soaked at maximum temperature for $30 \mathrm{~min}$

*Corresponding author: Muhammad Ali, Institute of Advanced Materials, Bahauddin Zakariya University, Multan-60800, Pakistan, Tel: +92-61-9210097; E-mail: muhammad.ali@bzu.edu.pk

Received October 22, 2014; Accepted November 13, 2014; Published November 20, 2014

Citation: Ahmad K, Ali M, Ibrahim A, Baig WM (2014) Optimising the Yield of Silicon Carbide Synthesised from Indigenous Biomass Husk using Different Catalysts. J Material Sci Eng 3: 147. doi:10.4172/2169-0022.1000147

Copyright: (C) $2014 \mathrm{Ahmad} \mathrm{K}$, et al. This is an open-access article distributed under the terms of the Creative Commons Attribution License, which permits unrestricted use, distribution, and reproduction in any medium, provided the original author and source are credited. 
Citation: Ahmad K, Ali M, Ibrahim A, Baig WM (2014) Optimising the Yield of Silicon Carbide Synthesised from Indigenous Biomass Husk using Different Catalysts. J Material Sci Eng 3: 147. doi:10.4172/2169-0022.1000147

and then allowed to cool at the same rate. Argon gas was purgedduring the whole course of heating and cooling at a rate of $0.1 \mathrm{lmin}^{-1}$. Oxidation of pyrolysed products was carried out at $750^{\circ} \mathrm{C}$ for $3 \mathrm{~h}$ in SentroTech (ST-1800) box furnace. The pyrolysed products after removal of unreacted carbon were identified by means of X-Ray diffraction analysis (using PANalytical Diffractometer) using $\mathrm{Cu}-\mathrm{K}_{\alpha}$ radiation. Following the XRD analysis, oxidised powder wastreated with $40 \%$ hydrofluoric acid in order to obtain pure $\mathrm{SiC}$ powder. Morphology of the desired product ( $\mathrm{SiC}$ powder) was examined by means of scanning electron microscope (SEM SU-3500). Energy dispersive spectrometry (EDS) coupled with SEM provided elemental analysis of the products.

\section{Results and Discussion}

Two peaks corresponding to $\mathrm{SiO}_{2}$ and $\mathrm{SiC}$ appeared in each diffractogram. The average value of $\mathrm{SiC}$ peaks was $2 \theta=35.977$, belong to (111) planes of $\beta$-SiC. All the peaks of $\mathrm{SiO}_{2}$ appeared approximately at same angles with an average value $2 \theta=21.771$. During continuous heating, $\mathrm{RH}$ powder undergoes various changes such as volatilisation of organic matter, graphitisation of carbon, crystallisation of amorphous silica, formation of silicon carbide whiskers and conversation of $\mathrm{SiC}$ whiskers into particles. Presence of silica was in the form of cristobalite. The Figurel shows a comparison of XRD patterns of the pyrolysed

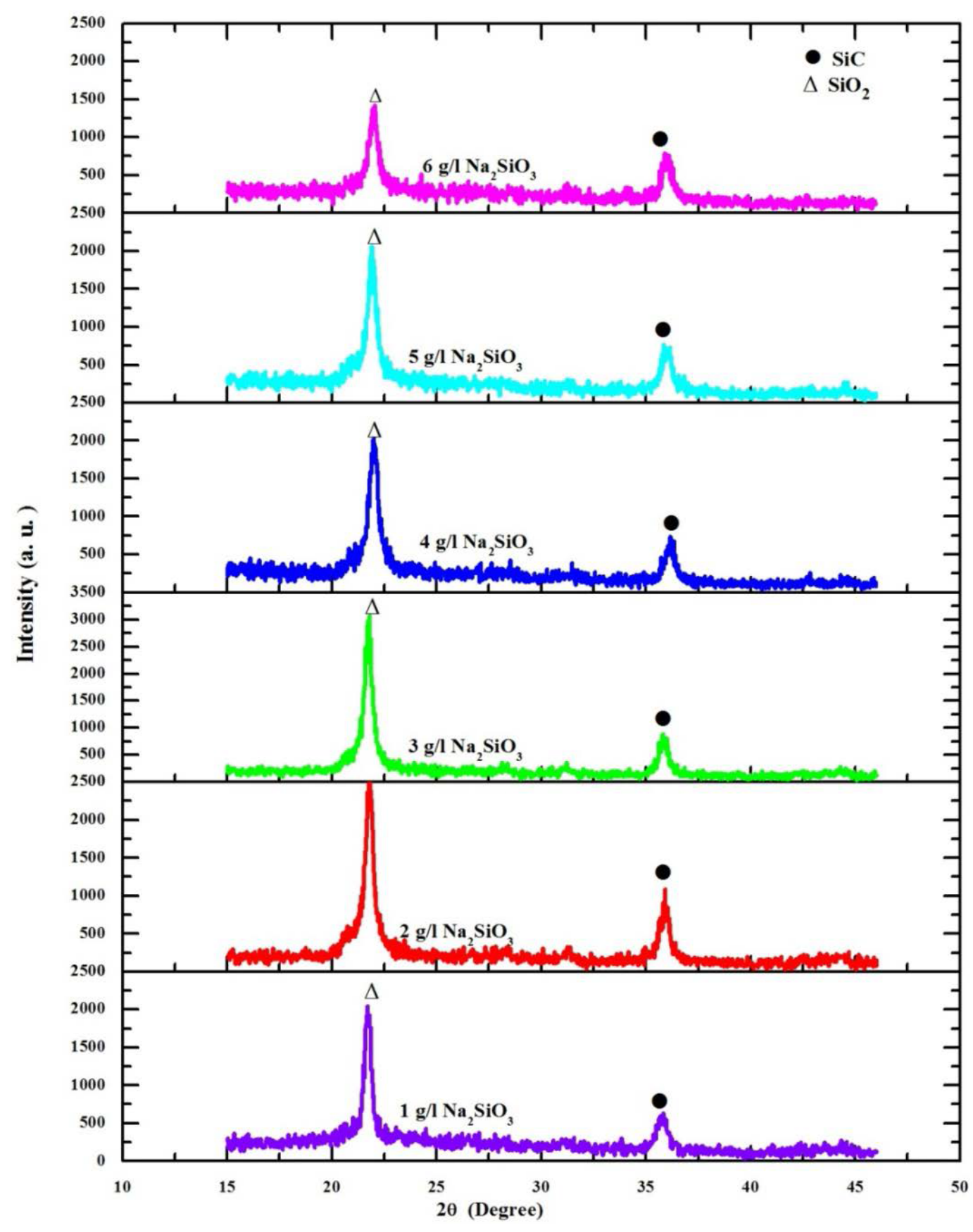

Figure 1: Comparison of XRD patterns of samples A1-A6. 
Citation: Ahmad K, Ali M, Ibrahim A, Baig WM (2014) Optimising the Yield of Silicon Carbide Synthesised from Indigenous Biomass Husk using Different Catalysts. J Material Sci Eng 3: 147. doi:10.4172/2169-0022.1000147

products from sodium silicate treated $\mathrm{RH}$. The highest peak of $\mathrm{SiC}$ was observed from pyrolysis of sample A2.

Figure $2 \mathrm{a}$ and $2 \mathrm{~b}$ shows micrographs of pure $\mathrm{SiC}$ powder obtained from samples A2 and B1. It is evident that silicate treated sample produced micron size carbide particles of irregular geometry whereas acid treatment fostered whiskers formation.

The EDS spectrum of A2 is shown in Figure 3 and corresponding elemental analysis given in Table 1 illustrate that the product contained $\mathrm{Si}, \mathrm{C}, \mathrm{O}$ and some other impurities present in the form of metallic oxides in the powder.

The effect of concentration of sodium silicate with respect to weight percent of $\mathrm{SiC}$ and $\mathrm{SiO}_{2}$ is shown in Figure 4. As the concentration of $\mathrm{Na}_{2} \mathrm{SiO}_{3}$ increased from 2-6 g/l, the high concentration caused a thick coating of silicate on the surface of RHs which promotes the formation of $\mathrm{SiO}_{2}$, because it actsas a barrier between the $\mathrm{SiO}$ gas in the media and the amorphous $\mathrm{C}$ in $\mathrm{RH}$ thereby delaying the pyrolysis reactions. Moreover,as the temperature of pyrolysis reactions increases from 1350 to $1550^{\circ} \mathrm{C}$ the formation of whiskers also decreases.Presence of

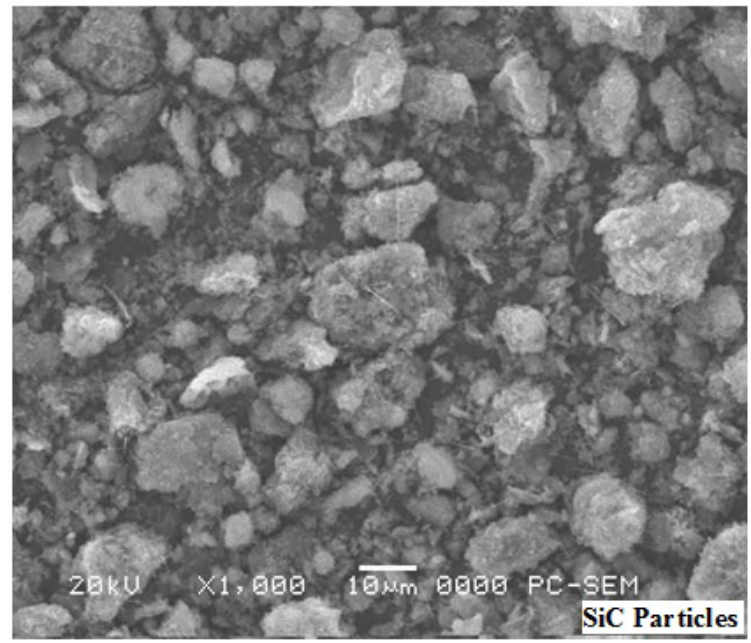

Figure 2a: SEM micrographs of SiC powder obtained from A2.

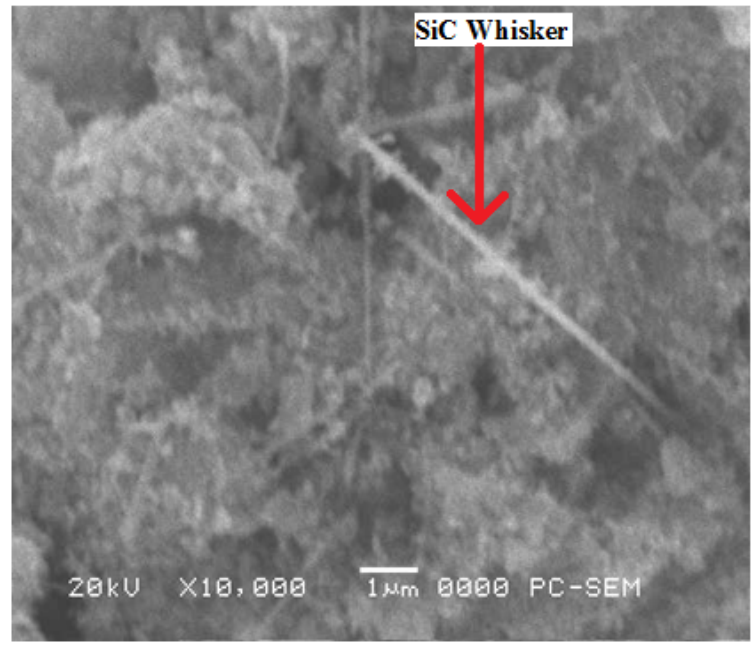

Figure 2b: SEM micrographs of SiC powder obtained from B1.

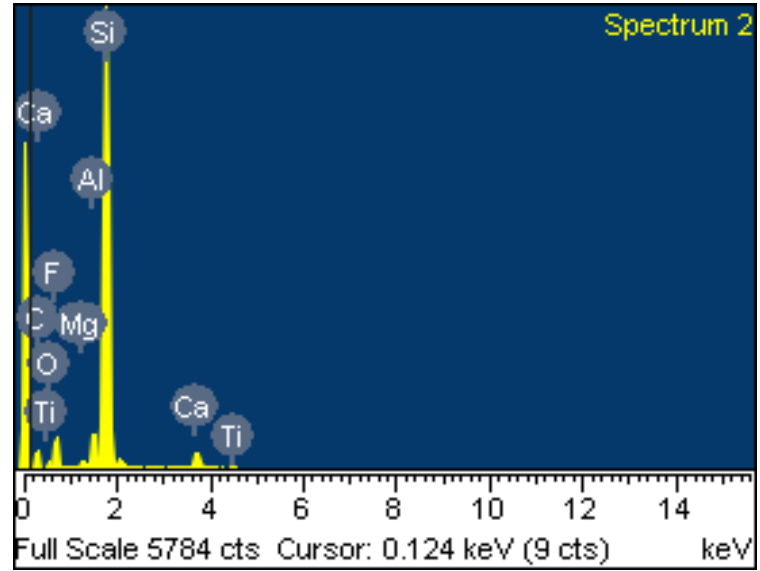

Figure 3: EDS Pattern of $\mathrm{SiC}$ powder

\begin{tabular}{|c|c|c|c|c|c|c|c|c|c|}
\hline Elements & $\mathrm{C}$ & $\mathrm{O}$ & $\mathrm{F}$ & $\mathrm{Mg}$ & $\mathrm{Al}$ & $\mathrm{Si}$ & $\mathrm{Ca}$ & $\mathrm{Ti}$ & Total \\
\hline Weight (\%) & 31.56 & 6.78 & 11.58 & 0.42 & 2.40 & 43.75 & 2.98 & 0.53 & 100 \\
\hline Atomic (\%) & 48.56 & 7.84 & 11.26 & 0.32 & 1.65 & 28.79 & 1.37 & 0.20 & \\
\hline
\end{tabular}

Table 1: Elemental Analysis of SiC powder.

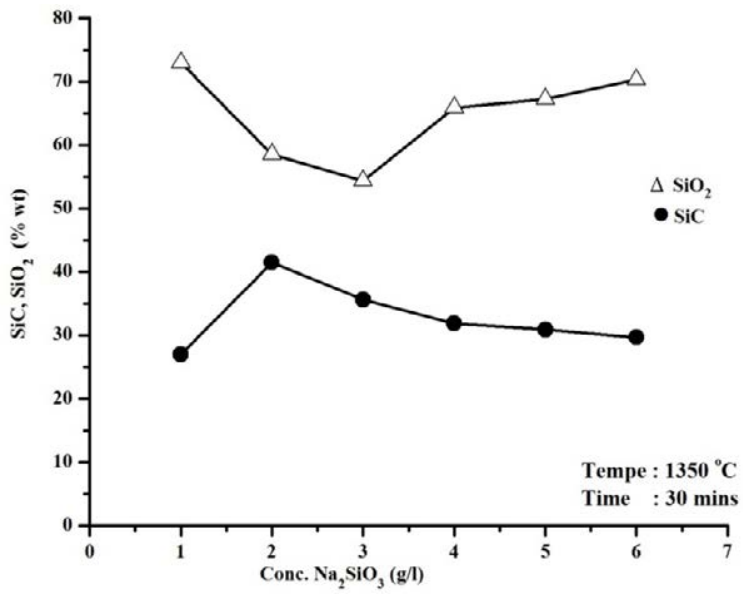

Figure 4: Effect of concentration of $\mathrm{Na} 2 \mathrm{SiO} 3$ on the yield of $\mathrm{SiC}$.

impurities such as $\mathrm{Mn}, \mathrm{K}, \mathrm{Ca}$ and other complex silicates facilitate the nucleation of whiskers of $\mathrm{SiC}$.

Calculated theoretical yield of $\mathrm{SiC}$ from $\mathrm{RH}$ is $58.3 \mathrm{wt} \%$ and practically the yield obtained was 51 wt\% [11]. Maximum yield obtained in this study was $41.46 \mathrm{wt} \%$ in case of sample A2.

\section{Conclusions}

Pre-treatments with sodium silicate proved effective to improve the yield of $\mathrm{SiC}$ from rice husks. Pyrolysis of pre-treated rice husks with 2 $\mathrm{g} / \mathrm{l}\left(\mathrm{Na}_{2} \mathrm{SiO}_{3}\right)$ resulted in maximum yield i.e. $41.46 \mathrm{wt} \%$. Pre-treatment with hydrochloric acid had slight effect on increasing the yield of the product.

\section{References}

1. Liu RJ, Zhang CR, Zhou XG, Cao YB (2004) Structural analysis of chemical vapor deposited $\beta-\mathrm{SiC}$ coatings from $\mathrm{C}_{\mathrm{H} 3} \mathrm{SiC}_{13}-\mathrm{H}_{2}$ gas precursor. J Cryst Growth 270: $124-127$

2. Stephen E, Agarwal SA (2004) Advances in Silicon Carbide Processing and Applications. Biomed Eng Online 4: 33. 
Citation: Ahmad K, Ali M, Ibrahim A, Baig WM (2014) Optimising the Yield of Silicon Carbide Synthesised from Indigenous Biomass Husk using Different Catalysts. J Material Sci Eng 3: 147. doi:10.4172/2169-0022.1000147

Page 4 of 4

3. Okutani T (2009) J Met Mater Min 19: 51-59.

4. Singh SK, Mohanty BC, Basu S (2002) Synthesis of SiC from rice husk in a plasma reactor. Bull Mater Sci 25: 561-563.

5. Krishnarao RV, Subrahmanyam J, Kumar TJ (2001) Studies on the formation of black particles in rice husk silica ash. J Eur Ceram Soc 21: 99-104.

6. Sun L, Gong K (2001) Silicon-Based Materials from Rice Husks and Their Applications. Ind Eng Chem Res 40: 5861-5877.

7. Kurama S, Kurama $\mathrm{H}(2008)$ The reaction kinetics of rice husk based cordierite ceramics. Ceram Int 34: 269-272.

8. Heimann RB (2003) Silicon carbide formation from pretreated rice husks. J Mater Sci 38: 4739-4744.
9. Sanai K, Jitcharoen J (2009) J Micro Soc Thai 23: 157-161.

10. Krishnarao RV, Mahajan YR (1995) Effect of acid treatment on the formation of $\mathrm{SiC}$ whiskers from raw rice husks. J Eur Ceram Soc 15: 1229-1234.

11. Janghorban K, Tazesh HR (1999) Effect of catalyst and process parameters on the production of silicon carbide from rice hulls. Ceram Int 25: 7-12.

12. Martinez V, Valencia MF, Cruz J, Mejia JM, Chejne F (2006) Production of $\beta-S i C$ by pyrolysis of rice husk in gas furnaces. Ceram Int 32: 891-897.

13. Singh SK, Mohanty BC, Basu S (2002) Synthesis of SiC from rice husk in a plasma reactor. Bull Mater Sci 25: 561-563. 